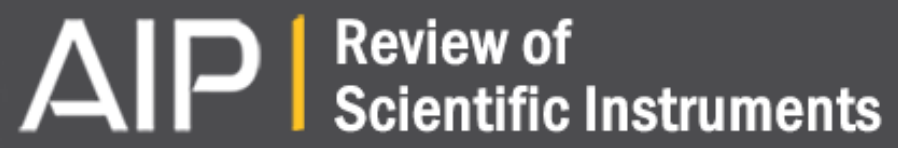

An atmospheric pressure high-temperature laminar flow reactor for investigation of combustion and related gas phase reaction systems

Patrick Oßwald and Markus Köhler

Citation: Review of Scientific Instruments 86, 105109 (2015); doi: 10.1063/1.4932608

View online: http://dx.doi.org/10.1063/1.4932608

View Table of Contents: http://scitation.aip.org/content/aip/journal/rsi/86/10?ver=pdfcov

Published by the AIP Publishing

\section{Articles you may be interested in}

A versatile elevated-pressure reactor combined with an ultrahigh vacuum surface setup for efficient testing of model and powder catalysts under clean gas-phase conditions

Rev. Sci. Instrum. 84, 094101 (2013); 10.1063/1.4818669

High temperature reaction kinetics of $\mathrm{CN}(\mathrm{v}=0)$ with $\mathrm{C} 2 \mathrm{H} 4$ and $\mathrm{C} 2 \mathrm{H} 6$ and vibrational relaxation of $\mathrm{CN}(\mathrm{v}=1)$ with $\mathrm{Ar}$ and $\mathrm{He}$

J. Chem. Phys. 138, 124308 (2013); 10.1063/1.4795206

Moving bed reactor setup to study complex gas-solid reactions

Rev. Sci. Instrum. 78, 085106 (2007); 10.1063/1.2760746

Combustion mechanism of liquid fuel spray in a gaseous flame

Phys. Fluids 17, 123301 (2005); 10.1063/1.2140294

On molecular transport effects in real gas laminar diffusion flames at large pressure

Phys. Fluids 17, 103601 (2005); 10.1063/1.1990198

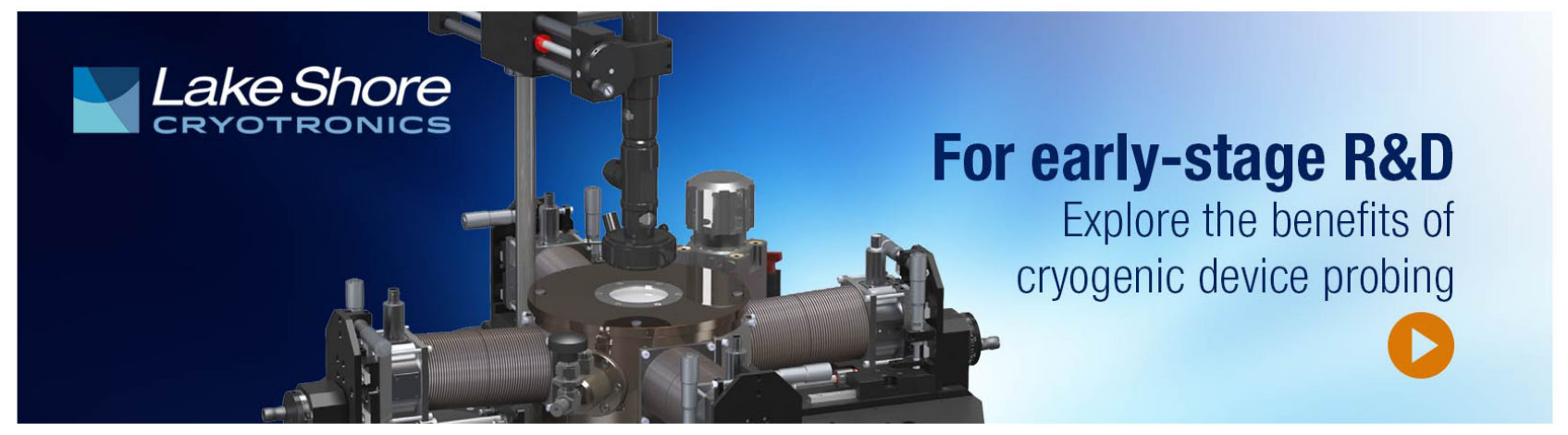




\title{
An atmospheric pressure high-temperature laminar flow reactor for investigation of combustion and related gas phase reaction systems
}

\author{
Patrick Oßwald and Markus Köhler \\ Institute of Combustion Technology, German Aerospace Center (DLR), Pfaffenwaldring 38-40, \\ D-70569 Stuttgart, Germany
}

(Received 6 July 2015; accepted 26 September 2015; published online 14 October 2015)

\begin{abstract}
A new high-temperature flow reactor experiment utilizing the powerful molecular beam mass spectrometry (MBMS) technique for detailed observation of gas phase kinetics in reacting flows is presented. The reactor design provides a consequent extension of the experimental portfolio of validation experiments for combustion reaction kinetics. Temperatures up to $1800 \mathrm{~K}$ are applicable by three individually controlled temperature zones with this atmospheric pressure flow reactor. Detailed speciation data are obtained using the sensitive MBMS technique, providing in situ access to almost all chemical species involved in the combustion process, including highly reactive species such as radicals. Strategies for quantifying the experimental data are presented alongside a careful analysis of the characterization of the experimental boundary conditions to enable precise numeric reproduction of the experimental results. The general capabilities of this new analytical tool for the investigation of reacting flows are demonstrated for a selected range of conditions, fuels, and applications. A detailed dataset for the well-known gaseous fuels, methane and ethylene, is provided and used to verify the experimental approach. Furthermore, application for liquid fuels and fuel components important for technical combustors like gas turbines and engines is demonstrated. Besides the detailed investigation of novel fuels and fuel components, the wide range of operation conditions gives access to extended combustion topics, such as super rich conditions at high temperature important for gasification processes, or the peroxy chemistry governing the low temperature oxidation regime. These demonstrations are accompanied by a first kinetic modeling approach, examining the opportunities for model validation purposes. (C) 2015 AIP Publishing LLC. [http://dx.doi.org/10.1063/1.4932608]
\end{abstract}

\section{INTRODUCTION}

Combustion processes are essential constituents of all human societies and have been a research target since time immemorial. The highly sophisticated utilization of combustion reactions in modern combustors has increased demand on the fundamental understanding of the underlying chemical and physical processes. In particular, the complex chemical reaction networks resulting from the radical chain reactions are still not fully understood even today and a detailed knowledge of the chemical reaction network is crucial, when pollutant formation or (auto) ignition processes are considered. ${ }^{1,2}$

Typical experiments for fundamental research on combustion chemistry are designed to provide simplified controlled environments due to the high complexity and interaction of individual processes. Consequently, most experiments do not exactly reproduce the conditions of technical combustors but provide the possibility to track the evolution of specific important features such as temperature, pressure, heat release, or most revealing, chemical species. Thus, many different approaches are needed to cover the full range of conditions and gather subsequent sets of information to describe complex technical systems. Shock tubes ${ }^{3,4}$ or rapid compression machines, ${ }^{5}$ for example, provide high control of pressure and temperature over a wide range. The accessible reaction time and applicable analytic techniques are, however, limited. Laminar premixed flames on the one hand are well suited to provide high temperature conditions, but the spatial extent of the reaction zone decreases with increasing pressure. For this reason, flames are typically observed at low pressure conditions for investigating fundamental reaction kinetics. On the other hand, reactor experiments provide access to high pressure $^{6-9}$ environments, while temperatures are typically lower compared to flames.

Countless reactor designs have been used for combustion research in the past century depending on the research problem and the coupled analytics. The following short overview summarizes some selected examples, rather than providing an entire relevant literature review. Important contributions regarding combustion reaction kinetics have been made, for example, with jet stirred reactors, ${ }^{10-12}$ representing the gas phase implementation of the continuous flow stirredtank reactor. Flow reactors have also widely been applied to combustion studies of various construction types. Flow conditions range from laminar ${ }^{13-16}$ to turbulent ${ }^{17,18}$ and operation conditions range from vacuum ${ }^{19,20}$ to the high pressure regimes $^{7-9}$ with pressures up to 100 bar. $^{6}$ Additionally, flow reactors are used to study specific radical reactions ${ }^{21}$ or as radical source. ${ }^{22,23}$ Operating temperatures are typically between 500 and $1300 \mathrm{~K}^{15,24}$ but are not limited to this range.

The full range of gas phase analyses may be coupled to a designated flow reactor experiment. Determination of the product composition can be performed at the reactor outlet $^{25-27}$ for a range of conditions, or even related to the 
spatial coordinate. ${ }^{28,29}$ However, proper treatment of initialization, ${ }^{30}$ which is connected to the temporal beginning of reaction, must be considered with great care when results are interpreted. For this purpose, typical well established and commercially available analysis techniques such as gas chromatography, ${ }^{17}$ mass spectrometry, ${ }^{31}$ or infrared spectroscopy $^{25}$ are applied. Also, highly sophisticated analytics, such as synchrotron based techniques, ${ }^{32}$ utilize flow reactors for combustion related elementary kinetics ${ }^{33,34}$ and pyrolysis experiments. ${ }^{16}$

In this work, we present a new high-temperature flow reactor experiment utilizing the powerful molecular beam mass spectrometry (MBMS) technique for detailed speciation. Temperatures up to $1800 \mathrm{~K}$ are feasible with this atmospheric pressure reactor, while the sensitive MBMS technique provides access to almost all chemical species involved in the combustion process, including highly reactive species such as radicals. ${ }^{35}$ The technique has proven many times to be of great value for the detailed investigation of reaction networks in flames ${ }^{36}$ of conventional ${ }^{37}$ and modern alternative fuels, ${ }^{38}$ such as alcohols. ${ }^{39}$ The experiment described here provides a consequent extension of our institutes experimental portfolio of validation experiments for combustion reaction kinetics, i.e., shock tubes ${ }^{40}$ laminar flames,${ }^{41}$ and low pressure flame speciation. ${ }^{35,42}$

\section{EXPERIMENTAL SETUP}

The schematic setup of the presented flow reactor experiment is shown in Fig. 1. The system consists of the hightemperature reactor, including the gas supplies and the coupled gas analyzer, i.e., a MBMS system. Gases are sampled directly from the reactor outlet at ambient pressure and transferred to the vacuum system of the time-of-flight mass spectrometer. The following chapter gives a detailed description of both parts, beginning with the MBMS system.

\section{A. Molecular beam mass spectrometry}

\section{The MBMS system}

The sampling setup and mass spectrometer are housed by a cubic vacuum vessel (Vacom, custom designed). The vessel is divided into two chambers, which are individually evacuated by turbo molecular pumps (first stage: Oerlikon Leybold, MAG W 2800 and ionization chamber: Oerlikon Leybold, MAG W 600 P) at high pump speeds (2400 1/s and $550 \mathrm{l} / \mathrm{s} \mathrm{N_{2 }}$, respectively) to realize sampling from atmospheric pressure. Pressures of the vacuum system are monitored and recorded using Bayard-Alpert/Pirani full range pressure gauges (Vacom, ATMION).

The two differential pumping stages are aligned horizontally to allow for gas sampling in the flow direction of the reactor. Gases are withdrawn by a handmade quartz cone (QGH Aachen, QGT Bad Harzburg, or QSIL Ilmenau) with an inner angle of $25^{\circ}, 1-2 \mathrm{~mm}$ wall thickness, and total height of approximately $80 \mathrm{~mm}$. This design follows experiences from flame sampling instruments ${ }^{43,44}$ and is designed to minimize disturbance ${ }^{45}$ of flow and temperature field while allowing proper quenching of chemical reactions. The cone is placed on a cooled flange (250 ISO-K) with double side sealing surfaces mounted at the front side of the vacuum vessel. A molecular beam is formed by a small orifice at the cone tip. For atmospheric pressure sampling, orifice diameters below $50 \mu \mathrm{m}$ are required. ${ }^{46}$ The molecular beam is skimmed $34 \mathrm{~mm}$ downstream of the nozzle tip using a Ni-skimmer (Beam Dynamics, model 76.2) before passing into the ion source of the spectrometer. The skimmer, with a total length of $76 \mathrm{~mm}$, is mounted to the valve seat of a $38 \mathrm{~mm}$ gate valve (VAT, custom designed), which allows for vacuum tight separation of both pumping stages. Skimmers with orifice diameters of $0.5-2.5 \mathrm{~mm}$ are available.

This configuration allows for molecular beam sampling at about $61 \mathrm{~mm}$ distance from the flange surface. For the present experiment, the reactor exhaust is placed in front of

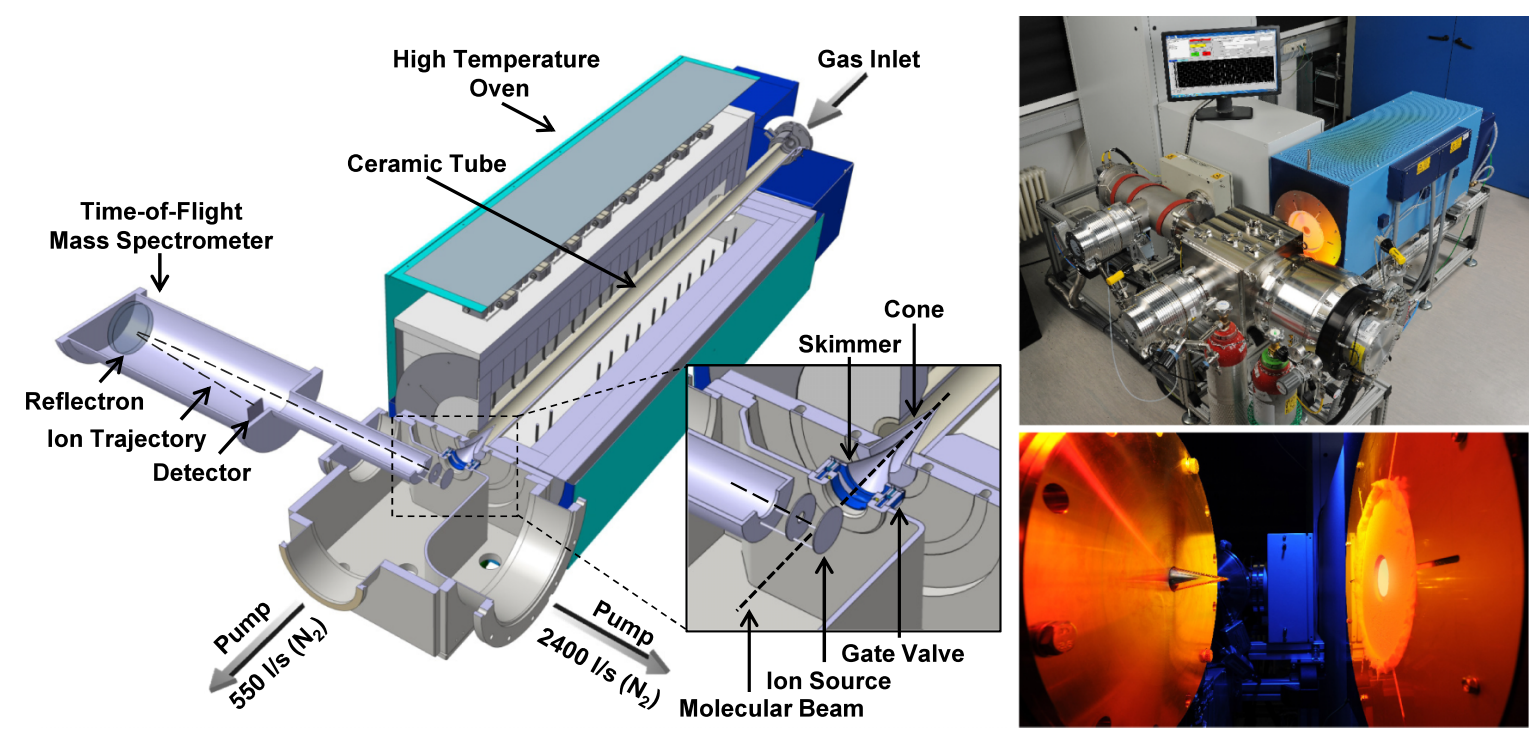

FIG. 1. Schematic DLR high-temperature flow reactor and photographs. The zoomed cutout shows a detailed view of the sampling interface and the ionization source separated by the gate valve. Note that the high-temperature oven is mounted on moveable rails and sampling is performed inside the tube at ambient pressure. 
the sampling nozzle, see Sec. II B for details. The oven is placed $31 \mathrm{~mm}$ (determined by exchangeable distance bolts) in front of this flange without any further connection. In the current configuration, sampling from atmospheric pressure is thus mandatory. Under operating conditions, pressures vary depending on the sampled gas temperature from $10^{-3}-10^{-4}$ mbar in the first pumping stage and from $10^{-5}-10^{-6} \mathrm{mbar}$ in the ionization chamber, respectively. This is sufficient for immediate quenching of any chemical reaction and the composition of the gas sample is conserved. ${ }^{32,47}$

Gas analysis is performed applying a custom designed time-of-flight mass spectrometer (Kaesdorf). The spectrometer was previously used in a low pressure flame sampling configuration $^{48,49}$ and updated with a new ion source and state-of-the-art electronics for the present experimental setup. The spectrometer is equipped with a two stage WileyMcLaren ion source and a reflectron providing a high mass resolution ( $\mathrm{R}=3000$ ). Ionization typically is performed using near threshold electron ionization (EI) in the range of 8-25 eV. Laser based photoionization techniques such as resonant enhanced multiphoton ionization ${ }^{49,50}$ are, however, also applicable at this ion source. The pulsed ionization and ion extraction allow for repetition rates up to $40 \mathrm{kHz}$. Post mass separation, via time-of-flight mass separator, high sensitivity ion detection is performed by a $40 \mathrm{~mm} \mathrm{Z}$-stack microchannel plate (Photonics). Signals are recorded via a multi-channel scaler (Fast Comtec, p7887). For typical measurements in the presented experimental setup, electron energies below the ionization of the used diluent $(\mathrm{Ar} ; 15.76 \mathrm{eV}$ ) are applied and signals are recorded with a repetition rate of $35 \mathrm{kHz}$ allowing for detection of species up to $m / z=260 \mathrm{amu}$. Note that nevertheless a sufficient argon signal is detectable due to its high fraction and the broad electron energy distribution. In this mass regime, the determination of the elemental composition in a $\mathrm{C} / \mathrm{H} / \mathrm{O}$ environment based on the exact mass is possible.

\section{Quantitative data evaluation}

Quantitative evaluation is possible following the same strategies as commonly applied for flames ${ }^{35,37,43,44}$ and reactor measurements. ${ }^{15,51}$ In general, the measured integrated ion signal $S$ of species $i$ can be related to its partial pressure at the probe tip (note that the partial pressure $p_{i}$ is related to the mole fraction $x_{i}$ for a constant pressure $p ; p_{i}=p=x_{i}$ ) by the following relation:

$S_{i}=p_{i} \cdot c \cdot S W \cdot D_{i} \cdot \varphi \cdot F K T(T) \cdot \int \sigma_{i}(\tau) \cdot f(E-\tau) d \tau$.

Here $c$ is an instrument factor, $S W$ is the number of sweeps measured, $D_{i}$ is a mass discrimination factor, $\varphi$ is the number of ionizing particles (photons or electrons), $F K T(T)$ is a temperature- and composition-dependent sampling function, and $\int \sigma_{i}(\tau) \cdot f(E-\tau) d \tau$ is the convolution of ionization cross section $\sigma_{i}(E)$ with the energy distribution $f(E)$ of the ionizing particles using the integration parameter $\tau$. In the present experiment, signals are measured in comparison to a reference species $R$ and thus Eq. (1) simplifies to
$\frac{S_{i}}{S_{R}}=\frac{x_{i}}{x_{R}} \cdot \frac{D_{i}}{D_{R}} \cdot \frac{\int \sigma_{i}(\tau) f(E-\tau) d \tau}{\int \sigma_{R}(\tau) f(E-\tau) d \tau}=\frac{x_{i}}{x_{R}} \cdot k_{i / R}(E)$,

where $k_{i / R}(\mathrm{E})$ is the species- and energy-dependent calibration factor for the species $i$ and the reference signal $R$. Typically for EI measurements the inert diluent (Ar) is used as the reference species. Note that the broad energy distribution of the ionizing electrons and the high concentration of diluent enable the measurement of a sufficient reference signal even at lower nominal energies. Various techniques are existent for the determination of a respective calibration factor. ${ }^{42,44,51}$ In principle, the same evaluation strategies as applied for flame analysis can be adapted for flow reactor measurements. ${ }^{15}$ Thus, just a brief description is given here.

For major species, i.e., product and reactant species, internal calibration based on mass conservation is applicable. A detailed description may be found in Refs. 15 and 44 and procedures can be transferred to the present experiments with slight modifications. In particular, (a) the mole fraction of the diluent can be approximated as constant, since the total number of moles does not change significantly at the conditions applied here and (b) element balances must be adapted for the very lean and rich cases accessible in flow reactor experiments, see supplementary material ${ }^{52}$ for details. However, direct measurement of the calibration factors versus $\mathrm{Ar}$ is feasible for all major species except $\mathrm{H}_{2} \mathrm{O}$. Calibration measurements are either done by using data referring to cold (i.e., non-reactive) reactor temperatures or using a commercial gas mixture containing $\mathrm{H}_{2} / \mathrm{CO} / \mathrm{CO}_{2}$ and $\mathrm{Ar} . \mathrm{H}_{2} \mathrm{O}$ may be calibrated applying the $\mathrm{O}$ balance (or $\mathrm{H}$ balance at lean conditions). Details may be found in the supplementary material. ${ }^{52}$ Calibration gases are applied using an evacuated ISO-KF tee which is placed directly in front of the quartz cone. Pressure can be regulated by reducing the pump speed at the outlet and the inlet gas flow rate. The pressure is adjusted for good signal-to-noise ratio while operation in the linear regime of the detector must be ensured at the same time.

Intermediate species are also calibrated using binary gas mixtures, either commercially available or mixed via appropriate mass flow controllers, whenever substances are available. For species unavailable as a cold gas sample, e.g. reactive radical species, estimation procedures are applicable. In particular, the relative ionization cross section (RICS) $\operatorname{method~}^{47}$ and direct application ${ }^{44}$ of Eq. (1) can be used once the system is properly characterized. Again, procedures from flame MBMS measurements can be used. Detailed descriptions can be found in Refs. 35, 42, 44, and 51 and in their respective supplemental content.

\section{B. High-temperature reactor}

The flow reactor primarily consists of an alumina $\left(\mathrm{Al}_{2} \mathrm{O}_{3}\right)$ ceramic tube placed in a high-temperature oven. The inner diameter is $40 \mathrm{~mm}$ and the total length of the reactor tube is $1497 \mathrm{~mm}$ including the first $51 \mathrm{~mm}$, which is the water cooled gas inlet made from stainless steel $(\mathrm{id}=16 \mathrm{~mm}$ ). Cooling water is tempered to a constant value of up to $80^{\circ} \mathrm{C}$ to prevent potential condensation of prevaporized liquid fuels. Gases are fed to the reactor by a DN-KF-16 flange equipped with a 
porous bronze plug (Pfeiffer Vacuum) to create homogeneous flow conditions and to serve as a flame barrier. The spatial centerline coordinate $x$ used in the following refers to the sealing surface of this inlet flange.

The high-temperature oven (Gero, Typ HTRH 40-1000) provides heated a length of $1000 \mathrm{~mm}$, which is divided into three zones $(200,400$, and $400 \mathrm{~mm})$. Each zone can be controlled individually. The temperature of each zone is measured, controlled, and recorded via a B-type thermocouple (TC) (Pt30Rh-Pt6Rh) placed inside the oven. Typically, as for all measurements presented herein, all zones are set to the same temperature, coupled to zone 3 , at the reactor outlet. Consequently, the actual temperature value (i.e., measured value of the zone 3 thermocouple) is referred to as the oven temperature $\mathrm{T}_{\text {Oven }}$ in the following. The oven is able to provide temperatures up to $1900 \mathrm{~K}$ and heating/cooling rates up to 500 $\mathrm{K} / \mathrm{h}$ are applicable. Note that above $1800 \mathrm{~K}$ problems with the sealing of the sampling cone have prohibited respective measurements. Typical measurement series are performed at constant inlet flow conditions and a monotonically decreasing oven temperature ramp is applied.

Composition analysis is realized by placing the tip of the sampling cone of the MBMS at the fixed position $x$ $=1471 \mathrm{~mm}$ downstream along the reactor centerline. This is still about $30 \mathrm{~mm}$ inside the ceramic tube. Physically, this is realized by placing the oven on rails to allow its translation relative to the MBMS system for maintenance. After passing the cone, exhaust gases are emitted to the ambient air and are withdrawn by a fume hood placed above the oven. However, since the ceramic tube is mounted at the reactor inlet only, thermal expansion does not significantly affect the effective reactor length. Expansion of around $20 \mathrm{~mm}$ at $1200 \mathrm{~K}$ takes place at the downstream end solely and does not affect the sampling position with respect to the reactor inlet.

Gasses, i.e., fuel, oxidizer (typically $\mathrm{O}_{2}$ ), and diluent (typically Ar) are premixed about $3 \mathrm{~m}$ upstream of the reactor inlet. Gas supply lines (4 $\mathrm{mm}$ id) are made from stainless steel, polyamide (PA) or polytetrafluoroethylene (PTFE) synthetic material. To prevent any self-sustaining reactions, high dilution of fuel and oxidizer is mandatory. In order to minimize additional heat release and ensure temperature control, a dilution of at least $99 \%$ argon is typically applied. Higher dilutions are possible but decrease the sensitivity. Gaseous compounds are metered by Coriolis mass flow controllers (Bronkhorst, Mini Cori-Flow M14, M13, and M12) allowing for precise, well characterized inlet conditions. Thermal mass follow controllers (Bronkhorst, Sevenstar, Tylan, range 0.1-15 slm $\mathrm{N}_{2}$ ) are also available to realize additional gas flows with less precision. In the present setup, total flow rates from around 5 to $20 \mathrm{slm}$ are feasible. The lower boundary is determined by back diffusion of ambient air to the sampling position, while the upper boundary is just limited by the available flow control arrangement.

Liquid fuels may be metered and vaporized using a homemade vaporizer for very small flow rates. The vaporizer is designed similar to those used in Refs. 42 and 51. The heated (up to $200^{\circ} \mathrm{C}$ ) stainless steel tube, filled with glass wool, is directly connected to the reactor inlet and the carrier (diluent) gas can be preheated before passing through the vaporizer. The liquid fuel is metered and applied to the vaporizer by a syringe pump. Liquid flow rates in the regime of $20-200 \mu \mathrm{l} / \mathrm{min}$ can be vaporized stable using 10 or $50 \mathrm{ml}$ syringes. Fuels with boiling points up to $250{ }^{\circ} \mathrm{C}$ (farnesane, tetradecane) have been vaporized successfully with this system. Note that the most stable vaporization is achieved when temperatures slightly below the boiling point are applied. Complete evaporation is, however, ensured due to the low total fuel fraction.

For typical conditions, a total flow of $10 \mathrm{slm}$ (standard liter per minute: $273 \mathrm{~K}$ and $1013 \mathrm{mbar}$ ) and 99\% Ar dilution, a cold gas $(300 \mathrm{~K})$ velocity of $14.6 \mathrm{~cm} / \mathrm{s}$, and Reynolds number $\operatorname{Re}=416$ can be calculated. Numbers change for 500, 1000, and $1500 \mathrm{~K}$ to $\mathrm{v}=24.3,48.6$, and $72.9 \mathrm{~cm} / \mathrm{s}$ and $\mathrm{Re}=279$, 170, and 130, respectively. Thus, laminar flow conditions can be assumed for all operating conditions. The reactor exhibits a relatively high diameter-to-length ratio (heated length) of $\mathrm{d} / \mathrm{L}=0.04$ which reduced the volume to surface ratio compared to previous approaches. ${ }^{15,51}$ For the present setup, the number of wall collisions is almost seven orders of magnitude below the molecular gas collision rate. For those reasons, heterogeneous reactions are neglected and plug flow behavior is assumed as first order approximation.

\section{CHARACTERIZATION}

The main focus of the presented experimental setup is to provide reliable validation data for chemical kinetic reaction mechanism. This application requires a careful characterization of the experimental boundary conditions to enable precise numeric reproduction of the experimental results. ${ }^{30}$ Most important for all chemical reactions is the proper knowledge of the temperature behavior. Thus, exhaustive measurements on the reactors temperature behavior are performed and presented in this section alongside the detailed uncertainty analysis of the system.

\section{A. Temperature}

Temperature profiles are measured along the reactor's longitudinal axis for various operating conditions. A thermocouple is mounted inside a ceramic rod ( $9 \mathrm{~mm}$ diameter) that can be placed at any position along the reactor centerline. The rod is positioned and moved through a tee mounted to the inlet flange to enable a simultaneous gas feed into the reactor. The thermocouple's bead is placed straight about $5 \mathrm{~cm}$ downstream of the rod's end to measure the centerline gas temperature or is bended to be placed directly at the inner wall to obtain the surface temperature. Two different thermocouple types (Newport Electronics) are used for the temperature measurements: K-type (NiCr-Ni), working temperature up to $1100 \mathrm{~K}$, and Stype (Pt10Rh-Pt), working temperature up to $1800 \mathrm{~K}$. Both thermocouples are $1600 \mathrm{~mm}$ in length, are neither isolated nor coated ${ }^{53}$ and exhibit a temperature uncertainty of less than $4 \mathrm{~K}$ by their specifications.

Temperature profiles are obtained by successive upstream translation of the thermocouple (rod) for a specific oven temperature and flow condition (Ar flow). Spatial distance is measured with respect to the reactor exit. The uncertainty due to thermal expansion of the probe arrangement is estimated 
to be less than $2 \%$ or $3 \mathrm{~cm}$, respectively. The temperatures are recorded when thermal equilibrium has been reached. A correction for radiative heat loss has not been applied due to the negligible temperature difference with respect to the reactor wall. $^{53}$

Measurements are performed for some gas flow rates $(5,10$, and 15 standard liter per minute; slm) as well as for different oven temperatures in the range of applied operating conditions. Representative results for the centerline temperature are summarized in Fig. 2 for oven temperatures ranging from $770 \mathrm{~K}$ to $1670 \mathrm{~K}$ for the target flow rate of $10 \mathrm{slm}$ Ar. A homogenous flat profile is seen in the heated section for all profiles. Note again that different types of thermocouples have been used. Agreement of results in the overlap region $(1270 \mathrm{~K})$ is sufficient and a discrepancy of $12 \mathrm{~K}$ is found. However, it should be noted that the deviation with respect to the ovens control thermocouples (i.e., the actual value of all zones) is significantly higher. Here, a systematic deviation of up to $25 \mathrm{~K}$ must be considered, especially for lower temperatures since these thermocouples are calibrated for the high temperature regime and the deviation disappears in the region of $1800 \mathrm{~K}$.

For the target flow conditions, no significant difference of wall and centerline temperature has been observed at $\mathrm{T}_{\text {Oven }}$ $=1273 \mathrm{~K}$. Also, the influence of total gas flow on the temperature profiles is found to be not very pronounced in the probed flow regime. In Fig. 3, a comparison of wall and centerline temperature profiles for different flow conditions is included (bottom right). Only the highest flow rate shows a slight downstream shift of the measured temperature profile which, however, still does not exceed the experimental uncertainty. Similar behavior has been seen for other temperatures and therefore, only the centerline temperature for the target flow conditions is considered for further analysis.

Since the temperature information for any oven temperature is mandatory for proper kinetic interpretation of the measured results, interpolation of the individual temperature profiles is desirable. Therefore, an arbitrary reference profile can be scaled according to the respective oven temperature. Figure 2 gives the result of this scaling approach (us-

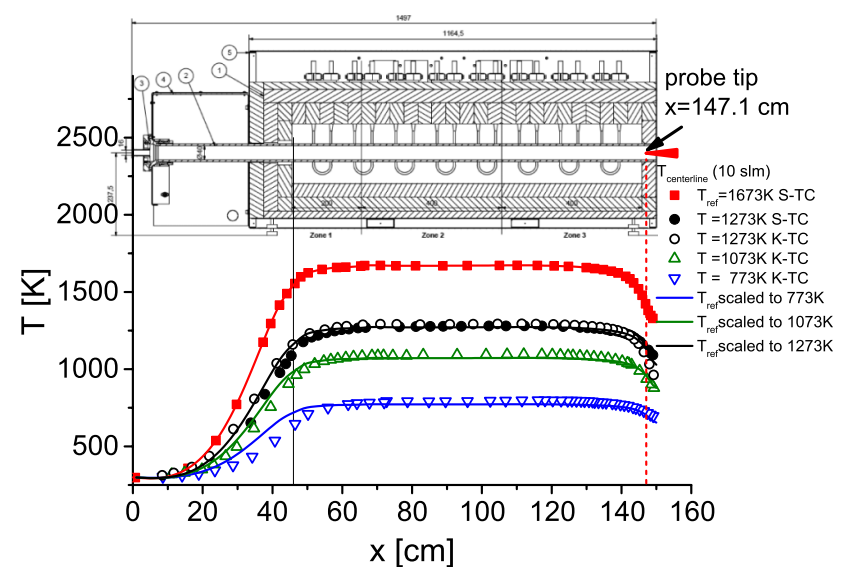

FIG. 2. Centerline temperature profiles for some constant oven temperatures (T). The lines represent the $\mathrm{T}_{\text {ref }}=1673 \mathrm{~K}$ profile scaled by the respective oven temperature ratio. Note that different thermocouple (TC) types are used for the appropriate temperature region.
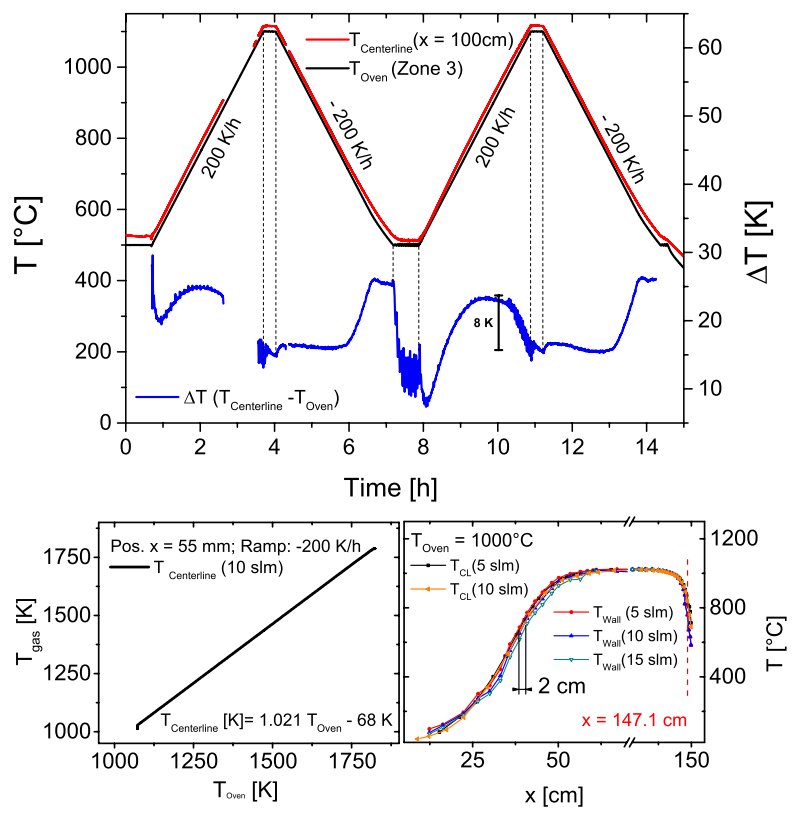

FIG. 3. Centerline (gas) temperature for continuous variation of the oven temperature for non-reactive flow (10 slm Ar) conditions (at $100 \mathrm{~cm}$ : top and $55 \mathrm{~cm}$ : bottom left). Axial temperature profiles for various flow conditions at constant oven temperature (bottom right).

ing $1673 \mathrm{~K}$ as reference profile) as lines compared to the respective measurements (symbols). A good reproduction of the measured profiles by this scaling approach can be stated for the relevant temperature range of the flow reactor.

For a closer examination of the intended continuous temperature ramps, distinct temperature measurements at a fixed centerline are performed and presented in Fig. 3 (top). A ramp speed of $200 \mathrm{~K} / \mathrm{h}$ has been chosen as a feasible compromise between averaging time per temperature interval and necessary total measurement time for a single condition. Again, values for $10 \mathrm{slm}$ and respective heating and cooling ramps are examined at a spatial position where the plateau region is reached, i.e., $x=100 \mathrm{~cm}$. Regardless of the systematic deviation of the oven thermocouple, proportional behavior of the centerline temperature is found in both directions. Some minor deviations are seen at the edges of the ramps. Decreasing the temperature, however, exhibits proportionality with respect to the actual oven temperature over a wider temperature interval. Also, the reactive measurements show higher reproducible results, when decreasing ramps are applied. For this reasons decay ramps are used in general. Besides the absolute deviation of both values also observed in the isothermal measurements as stated above, a discrepancy of about $8 \mathrm{~K}$ can be observed between temperature decay and rise. This may be explained by the thermal inertia of the system.

To account for this effect, a calibration is performed at the rising edge of the temperature profile $(x=55 \mathrm{~cm})$, which is identified as a sensitive position. Results for the decay ramp $200 \mathrm{~K} / \mathrm{h}$ are also presented in Fig. 3 (top). Again, strict proportionality of the oven temperature and gas temperature is found with the exception for the ends of the measured interval. Based on this finding, a specific scaling law can be derived to 
obtain a profile for any oven temperature,

$T(x)[K]=\left(T_{\text {ref }}(x)-T_{0}\right) \cdot \frac{1.0205 \cdot T_{\text {Oven }}-68 K-T_{0}}{T_{\text {ref }}(55 \mathrm{~cm})-T_{0}}+T_{0}$.

Here, $T(x)$ is the centerline temperature at the reactor coordinate $x$ at the (measured) oven temperature $T_{\text {Oven }}$. As the reference temperature, $T_{\text {ref }}$ values of the profile at $T_{\text {Oven }}$ $=1673 \mathrm{~K}$ have been found to give a proper reproduction of the measured temperature profiles. $T_{\text {ref }}(55 \mathrm{~cm})$ is the respective temperature at the position $x=55 \mathrm{~cm}$ and $T_{0}$ is the inlet gas temperature. Note that this scaling law is strictly applicable only for a temperature decay rate of $200 \mathrm{~K} / \mathrm{h}$ with a total inlet volume stream of $10 \mathrm{slm}$ using $\mathrm{Ar}$ as diluent. However, since no huge sensitivity of the temperature profiles on the total volume flow is found, the approach may be transferred to other conditions as a first approximation.

\section{B. Uncertainty and reproducibility}

To examine the stability of the system, reactive MBMS measurements of $\mathrm{CH}_{4}$ are conducted and repeated over a longterm period. A stoichiometric $\mathrm{CH}_{4} / \mathrm{O}_{2}$ mixture diluted in $99 \%$ Ar has been measured, applying the conditions mentioned above with $10 \mathrm{slm}$ total volume flow and a temperature decay ramp of $200 \mathrm{~K} / \mathrm{h}$. Reproducibility of the results is excellent and the obtained profiles agree within $3 \mathrm{~K}$. Additionally, the influence of different total flow rates, diluents ( $\mathrm{Ar}$ and $\mathrm{He}$ ), and temperature ramps are examined. Table I summarizes specific ignition temperatures determined for a variety of conditions based on the peak value of a combustion intermediate $\left(\mathrm{C}_{2} \mathrm{H}_{4}\right)$ of the $\mathrm{CH}_{4}$ oxidation. Again, the temperatures for ramps with increasing and decreasing temperatures are compared.

In general, the findings of the thermocouple measurements at non-reactive conditions are confirmed. The temperature decay provides a more stable and reproducible result compared to the temperature increase procedure. However, the hysteresis, i.e., the temperature difference seen for both ramp directions, is more pronounced than expected from the thermocouple measurements. According to the species profiles, results are shifted by $20 \mathrm{~K}$ on the temperature axis (compare Fig. 4), while only $8 \mathrm{~K}$ are found in non-reactive gas temperature measurements (see Fig. 3). This hysteresis appears to

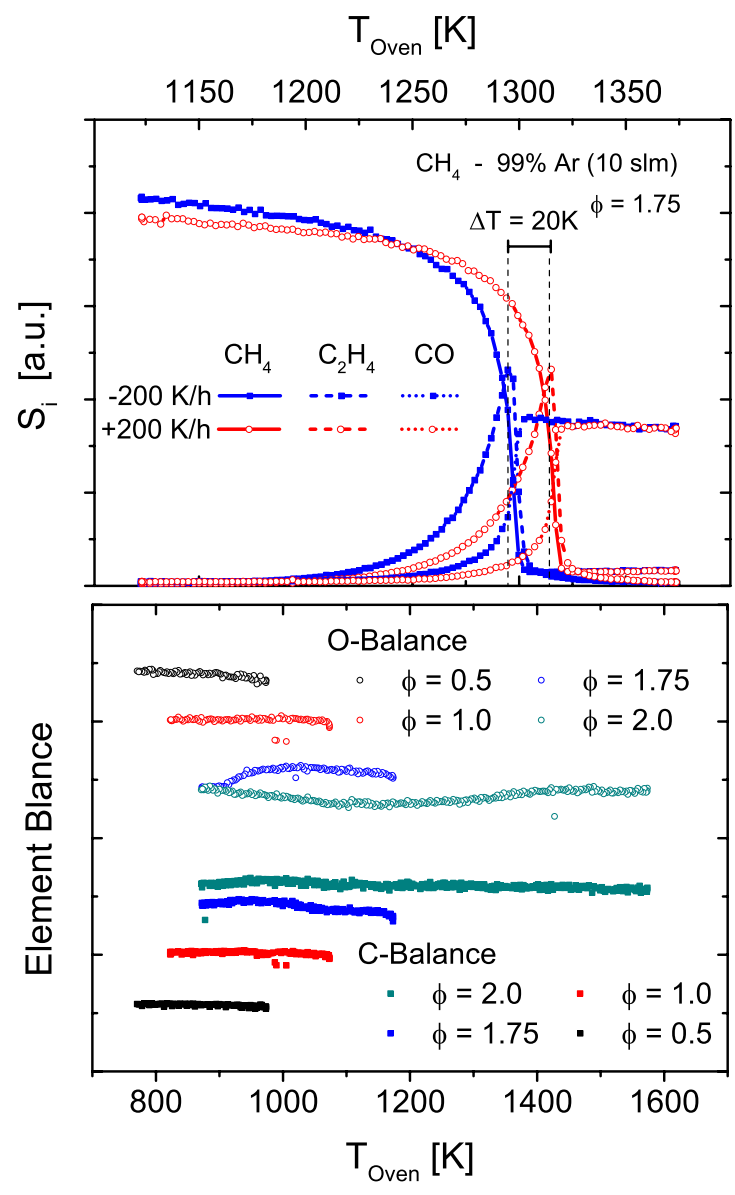

FIG. 4. Top: fuel $\left(\mathrm{CH}_{4}\right)$, intermediate $\left(\mathrm{C}_{2} \mathrm{H}_{4}\right)$, and product $(\mathrm{CO})$ profiles for a fuel rich $(\phi=1.75)$ methane measurement, when heating (red) and cooling (blue) oven temperature ramps are applied. Bottom: $\mathrm{C}$ and $\mathrm{O}$ atom balances for varying stoichiometries of ethylene $\left(\mathrm{C}_{2} \mathrm{H}_{4}\right)$ oxidation for all measured oven temperatures ranging from pure reactants to products. Note that all species are calibrated by direct cold gas measurements and the element balance was not used for calibration of this series.

be almost independent from other flow parameters (compare Table I). Similar results are obtained with changing ramp speed. Measurements under comparable conditions (i.e., ramp direction, temperature interval per measurement) only show a $4 \mathrm{~K}$ deviation in the $\mathrm{C}_{2} \mathrm{H}_{4}$ maximum for $66 \mathrm{~K} / \mathrm{h}$ vs. $200 \mathrm{~K} / \mathrm{h}$ ramp speed. When higher flow rates are applied, in contrast to the heating rate, the absolute temperature determined for

TABLE I. Comparison of ignition temperatures of $\mathrm{CH}_{4}$ oxidation $\left(\phi=1 ; 99 \%\right.$ dilution) for increasing $\left(\mathrm{T}_{\text {up }}\right)$ and decreasing $\left(\mathrm{T}_{\text {down }}\right)$ temperature ramps of different ramp speeds, total flow rates $(\dot{V})$, and diluents. Resulting velocities $(v)$ and residence times $(\tau)$ are also given.

\begin{tabular}{lcccccrc}
\hline \hline $\begin{array}{l}\dot{V} \\
(\mathrm{slm})\end{array}$ & $\begin{array}{c}v(300 \mathrm{~K}) \\
(\mathrm{Cm} / \mathrm{s})\end{array}$ & $\begin{array}{c}\tau(1000 \mathrm{~K} / 1 \mathrm{~m}) \\
(\mathrm{s})\end{array}$ & $\mathrm{Gas}$ & $\begin{array}{c}\text { Ramp speed } \\
(\mathrm{K} / \mathrm{h})\end{array}$ & $\begin{array}{c}\mathrm{T}_{\text {up }} \\
\left({ }^{\circ} \mathrm{C}\right)\end{array}$ & $\begin{array}{c}\mathrm{T}_{\text {down }} \\
\left({ }^{\circ} \mathrm{C}\right)\end{array}$ & $\begin{array}{c}\Delta \mathrm{T} \\
\left({ }^{\circ} \mathrm{C}\right)\end{array}$ \\
\hline 5 & 7 & 4.1 & $\mathrm{Ar}$ & 200 & 980 & 957 & 23 \\
10 & 15 & 2.1 & $\mathrm{Ar}$ & 200 & 1041 & 1021 & 20 \\
10 & 15 & 2.1 & $\mathrm{Ar}$ & 200 & 1042 & 1020 & 22 \\
15 & 22 & 1.4 & $\mathrm{Ar}$ & 200 & 1081 & 1064 & 17 \\
20 & 29 & 1.0 & $\mathrm{Ar}$ & 200 & 1124 & 1101 & 23 \\
10 & 15 & 2.1 & $\mathrm{Ar}$ & $400 / 66.6$ & 1048 & 1028 & 20 \\
10 & 15 & 2.1 & $\mathrm{He}$ & 200 & 1058 & 1039 & 19 \\
15 & 22 & 1.4 & $\mathrm{He}$ & 200 & 1096 & 1079 & 17 \\
\hline \hline
\end{tabular}


distinct features is shifted towards higher temperatures. This, however, is not unexpected due to the decrease in residence time and the changed heat transfer.

Considering the discrepancy between different thermocouple types as well as the observed hysteresis beyond the thermal inertia, an absolute uncertainty of the temperature below $20 \mathrm{~K}$ can be reasonably assumed. It should be noted that the systematic deviation $\left(T_{\text {Oven }} \approx T_{\text {gas }}-25 \mathrm{~K}\right.$ ) determined for the temperature control circuit of the oven is somewhat above this value. However, due to the excellent temperature reproducibility, a relative precision of the measured temperatures of $\pm 5 \mathrm{~K}$ or better can be stated for the present reactor experiment.

Stability of the measured peak intensities are comparable to other MBMS systems, ${ }^{15,35,43,54}$ i.e., reproducibility of an individual $\mathrm{m} / \mathrm{z}$ signal is better than $5 \%-10 \%$ depending on the specific signal-to-noise ratio. The resulting uncertainty of the determined mole fraction values, however, is highly dependent on the applied calibration method. For species, where direct calibrations measurements are applicable, typically an uncertainty up to $20 \%$ is stated since two measurements and the uncertainty of the used calibration gas composition must be considered. Figure 4 gives an example of the total $\mathrm{C}$ and $\mathrm{O}$ balance obtained from the mole fraction profiles of different $\mathrm{C}_{2} \mathrm{H}_{4}$ fueled measurements with varying stoichiometry. The flat profiles over the whole temperature interval give evidence of consistent data with an average error less than $20 \%$. However, when estimation procedures are applied to derive a calibration factor, the uncertainty can be much higher in the order of 2-4. Details may be found in Refs. 15, 42, and 44 and in their respective supplemental content.

\section{QUANTITATIVE SPECIES PROFILES}

The following chapter summarizes the first results obtained from the presented reactor experiment. The results are selected to adumbrate the range of conditions, fuels and applications to be examined; starting from well-known gaseous fuels such as methane and ethylene, investigations at conditions with well-known gas phase reaction kinetics, liquid fuels, and fuel components important for technical applications in gas turbines and combustion engines are examined. Here, examination of the full reaction network of novel fuels can be observed including soot precursor chemistry and radical species.

Besides the application for detailed investigation of novel fuels and fuel components, the superior range of operating conditions also gives access to extraordinary combustion applications such as super rich conditions at high temperatures, important for gasification processes, or the peroxy chemistry governing the low temperature oxidation regime.

\section{A. Gaseous fuels: General structure}

For validation of the present reactor experiment well characterized gaseous fuels, i.e., methane and ethylene, are measured for a wide range of stoichiometries. Measurements are performed at $99 \%$ dilution (Ar) applying a cold inlet velocity of $14.6 \mathrm{~cm} / \mathrm{s}$ at $300 \mathrm{~K}$ (corresponding to a total flow

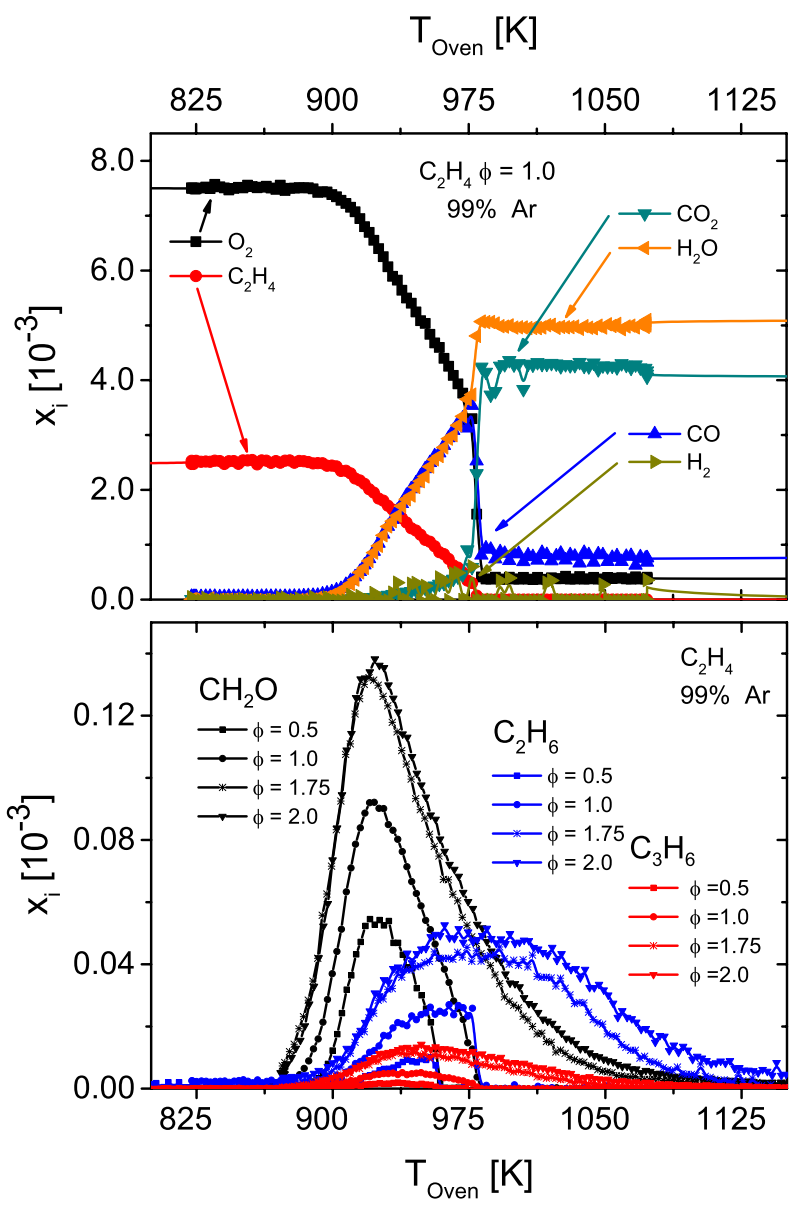

FIG. 5. Major species (top: $\phi=1$ only) and selected intermediates (bottom) for various ethylene stoichiometries. Mole fraction profiles for the intermediates formaldehyde $\left(\mathrm{CH}_{2} \mathrm{O}\right)$, ethane $\left(\mathrm{C}_{2} \mathrm{H}_{6}\right)$, and propene $\left(\mathrm{C}_{3} \mathrm{H}_{6}\right)$ are shown.

rate of $10 \mathrm{slm}$ ). Temperature decay ramps with $200 \mathrm{~K} / \mathrm{h}$ are performed and results are given as a function of the actual oven temperature (zone 3). See Sec. III A for details. The full dataset with all quantitative species profiles is available in the supplementary material. ${ }^{52}$

Representative results are given in Fig. 5. The general structure of results may be seen from the major reaction species (shown for ethylene, $\mathrm{C}_{2} \mathrm{H}_{4}$ measured at $\phi=1.0$ ), i.e., product and reactant species. Up to a certain temperature, the unchanged reactant species like fuel and oxygen are measured in unchanged quantities before initial fuel consumption can be observed. First, consumption of the oxidizer is typically observed in lesser degree or at higher temperatures, respectively. However, for small fuel molecules and lean conditions, fuel and oxidizer decay is observed to be similar.

The temperature range, where reactions can be observed is terminated when the reactor temperature is sufficient to enhance the radical pool to a certain level, i.e., the rate of chain branching reactions is fast enough. This (reactor) temperature, where rapid consumption of reactants is enabled just within the actual residence time, can be interpreted as ignition temperature for the specific condition. This is observed alongside with the complete conversion of reactants and a stable composition of products is detected. For rich conditions, a continuous 
transition from reactants to products is observed over a specific temperature range rather than the prompt conversion observed under stoichiometric or lean conditions. Also, additional reactions may be observed beyond ignition, see Section IV C.

The initial fuel decomposition is causally determined alongside the occurrence of combustion intermediates. Figure 5 summarizes the profiles of some typical intermediate species detected from ethylene oxidation for various stoichiometries. Due to the higher carbon content, the concentration of most intermediates increases with higher stoichiometry. Typically, a shift of the reaction zone towards higher temperatures alongside with an expansion of the respective temperature range is also observed with increasing stoichiometry.

The molecular beam sampling technique in principle allows for the detection of even highly reactive species such as radicals ${ }^{35}$ which has been demonstrated in many flame experiments. ${ }^{42,43,54-56}$ However, great care must be given to exclude interferences from fragment ions produced in the ion source of from larger parent ions even at the applied soft ionization condition. In the present experiment, radical detection is even more challenging due to the high dilution of reactants (and consequently intermediates) and the typically low fraction of reactive compounds. However, the superior sensitivity of the presented experiment is shown in Fig. 6 by means of the allyl radical profile obtained from fuel rich $(\phi=2.0)$ methane conditions. Potential fragmentation from propene was checked and can be excluded here. The profile is confirmed by kinetic modeling results using the broadly validated USC-II mechanism, ${ }^{57}$ see Section V for details. The measured peak mole fractions are in the order of a couple of ppb, which is pretty close to the detection limit as can be seen from the poor signal-to-noise ratio $(\sim 1: 1)$ of the profile. Note that the detection limit of an individual species is highly dependent on the applied ionization condition as well as the species ionization cross section and a general sensitivity up the ppb regime cannot be derived. To the best of our knowledge, this is the first flow reactor for combustion studies allowing for radical detection that applies the MBMS technique at atmospheric conditions.

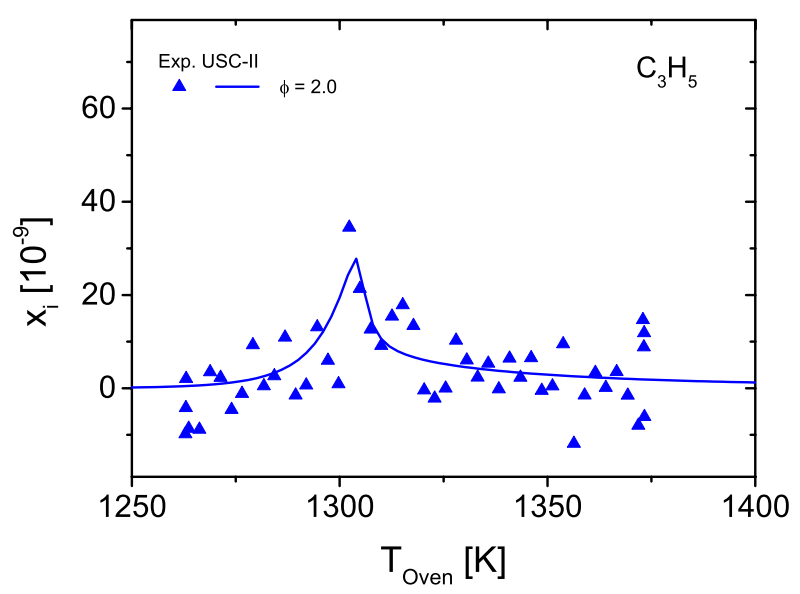

FIG. 6. Allyl radical measured in the $\mathrm{ppb}$ regime for fuel rich methane conditions, measurement (symbols) is confirmed by the modeling result (line).

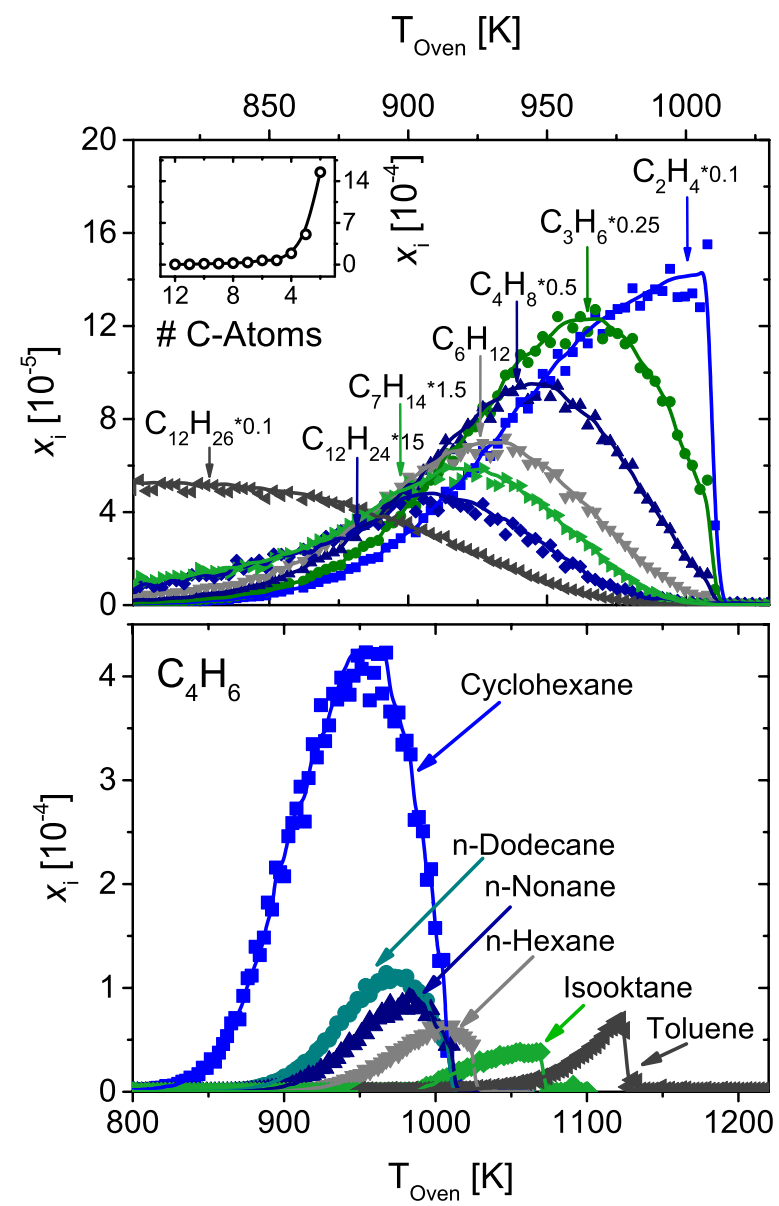

FIG. 7. Mole fraction profiles for liquid fuels. Top: alkenes measured during the oxidation of dodecane $\left(\mathrm{C}_{12} \mathrm{H}_{26}\right)$. Profiles are scaled for comparison (note scaling factor) and peak values are compared at the inset. Bottom: Butadiene profiles from various liquid fuels measured at stoichiometric conditions.

\section{B. Liquid fuels}

Most fuels of technical relevance, especially for transportation purposes, are liquid and must be vaporized for the investigation of their gas phase reaction chemistry. The present reactor experiment can be equipped with a vaporizer optimized for the specific demands of very small fuel flow rates. Figure 7 gives selected results for some liquid fuels including the oxidation of a prevaporized n-dodecane $\left(\mathrm{C}_{12} \mathrm{H}_{26}\right)$ measurement for a stoichiometric mixture. Dodecane may serve as an aliphatic model compound for jet or diesel fuels. Measurements are performed at the same conditions (dilution, flow conditions, temperature ramps, etc.) as applied for the gaseous fuels mentioned above.

Figure 7 (top) summarizes the (mono unsaturated) alkene intermediates $\left(\mathrm{C}_{12}\right.$ and $\left.\mathrm{C}_{7}-\mathrm{C}_{2}\right)$ detected during dodecane decay. 1-alkenes are the primary stable product of the $\mathrm{C}-\mathrm{C}$ scission reaction sequence ${ }^{58,59}$ (followed by scission of a $\mathrm{C}-\mathrm{H}$ bond). Note that the missing alkenes $\left(\mathrm{C}_{11} \mathrm{H}_{22}-\mathrm{C}_{8} \mathrm{H}_{16}\right)$ are also detected but are omitted for clarity of presentation. Their profile shapes are almost identical to $\mathrm{C}_{12} \mathrm{H}_{24}$ and $\mathrm{C}_{7} \mathrm{H}_{14}$. The subsequent steps of the dodecane decomposition can be clearly derived from the sequence of peak temperatures alongside the strong increase of short chained alkene mole fractions. The presented results demonstrate the possibility of 
direct observation of the fuel destruction pathway for specific fuel molecules and underline the high value of this kind of experiment for kinetic model development.

In many cases, the pollutant emissions from a technical combustion process are directly linked to the chemical structure of the used fuel or fuel blend. ${ }^{36,38}$ A direct comparison of the peak concentration of a specific intermediate measured from different fuels under comparable conditions allows for an estimation of the potential formation of pollutants. An example is presented in Fig. 7 for 1,3-butadiene $\left(\mathrm{C}_{4} \mathrm{H}_{6}\right)$, measured at different model fuel compounds: n-hexane, nnonane, n-dodecane, isooctane, cyclohexane, and toluene. Even though all fuels are investigated under identical conditions, i.e., stoichiometry, dilution, etc., a significant difference in the produced amount of the carcinogenic soot precursor 1,3-butadiene is seen during the oxidation reaction. Extraordinarily high amounts are found for the naphthenic fuel compound (cyclohexane), which is associated with its primary ring opening reaction. ${ }^{60}$ Also, a clear dependence on the backbone chain length can be determined for the $n$ alkanes. Analogous conclusions can be drawn for benzene (not shown), where, the highest concentrations are measured for the aromatic compound (toluene), as expected.

\section{High temperature regime: Gasification processes}

In contrast to flame experiments, a flow reactor is not limited to any flame stabilization criteria. This enables detailed speciation even for the harsh conditions, where flames cannot be stabilized, including pyrolysis and superior fuel rich conditions, for example. Especially the very fuel rich $(\phi=2.5$ and higher) operating conditions of gasification reactors in combination with the long reaction time scales are a topic of recent research projects. ${ }^{61}$ This non-catalytic partial oxidation (POX) of a hydrocarbon fuel is an important industrial process for producing syngas. However, knowledge about chemical kinetics is rather limited. Even for simple fuels such as methane, the established reaction models provide inconsistent predictions at these conditions. ${ }^{62}$ The proposed flow reactor enables insights into reactions linked to POX conditions and allows for systematic investigations not achievable in flames.

An example from a recent study ${ }^{63}$ is given in Fig. 8 (top panel), obtained from the present reactor. Here, methane and an equivalent amount of $\mathrm{CO}_{2}$ are investigated. The stoichiometry is $\phi=2.5$, dilution is somewhat higher $(99.5 \%$ ), while other parameters are similar to those described above. Corresponding residence times range from ca. $1.8 \mathrm{~s}(1200 \mathrm{~K})$ to $1.2 \mathrm{~s}(1750 \mathrm{~K})$. From these measurements, it is obvious that further reactions are taking place in the post ignition regime, i.e., above $1400 \mathrm{~K}$. For these conditions, a conversion of $\mathrm{CO}_{2}$ to $\mathrm{CO}$ can be observed alongside some intermediates present only in the high temperature regime $\left(\mathrm{C}_{2} \mathrm{H}_{2}\right.$ is shown as an example). Comparisons to typical models for methane combustion like the GRI 3.0 (Ref. 64) or USC-II ${ }^{57}$ reveal large discrepancies for the high temperature region even for major species like $\mathrm{CO}$ and $\mathrm{CO}_{2}$ that are usually very well covered for typical combustion conditions; see Section V and Ref. 63 for details.
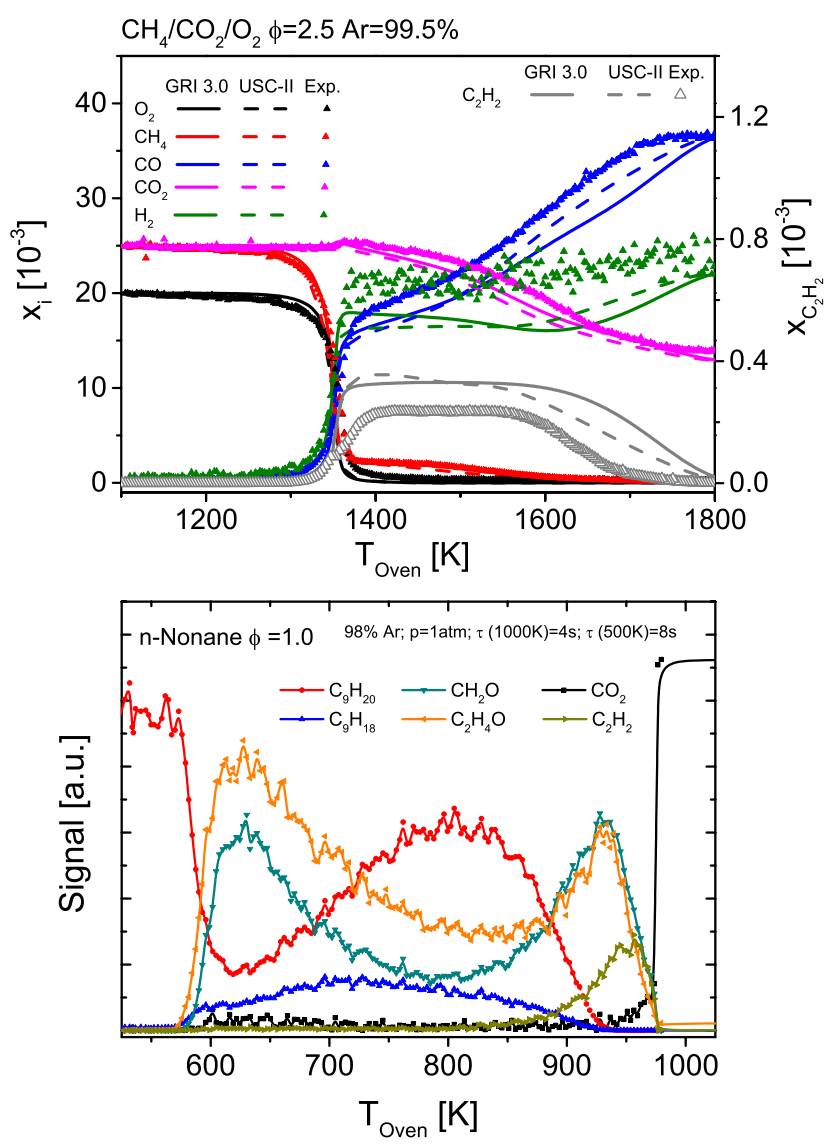

FIG. 8. Top: fuel rich $(\phi=2.5)$ methane oxidation for partial oxidation conditions, ${ }^{63}$ comparison of experiment (symbols), and model predictions (lines). Bottom: low temperature oxidation of $\mathrm{n}$-nonane.

\section{Low temperature regime: Low temperature chemistry}

Another domain, where flow and jet-stirred reactors are typically applied is for low temperature chemistry. This low temperature chemistry ${ }^{2}$ is of crucial interest for ignition processes in piston engines, especially for novel concepts like HCCI (homogeneous charge compression ignition).

Some classes of fuel molecules (e.g., long chained alkanes) are known to exhibit high reactivity even at temperatures as low as $600 \mathrm{~K}$. Here, $\mathrm{O}_{2}$ addition to hydrocarbon radicals enables a chain branching reaction channel in the subsequent peroxide destruction, ${ }^{2}$ enhancing the systems' reactivity. Further increase of temperature enables a competing reaction channel (chain propagation) resulting in decreased reactivity. Since the systems' reactivity decreases with increasing temperature, this is typically called the region of negative temperature coefficient ${ }^{65}$ (NTC).

Even though the present experiment is optimized for the high temperature region, low temperature chemistry can be examined. Figure 8 (bottom) gives an example measurement of n-nonane (99\% dilution, $\phi=1.0$ ). Since the reaction rate in the low temperature regime is still noticeably slower than at higher temperatures, the residence time must be increased significantly, i.e., total flow rate is only $5 \mathrm{slm}$ corresponding to residence times above $4 \mathrm{~s}$. At these conditions the expected low temperature reactivity can be observed (compare fuel decay at $630 \mathrm{~K}$ ) followed by the NTC region with increasing fuel 
fraction. Finally, the transition to the high temperature regime, where reactions are driven by the chain bracing reactions of the $\mathrm{H} / \mathrm{O}_{2}$ system, is indicated by the complete fuel consumption and the formation of hydrocarbon intermediates and $\mathrm{CO}_{2}$. It should be noted that the composition of the intermediate species pool changes significantly from one reaction domain to the other (compare formaldehyde, acetylene, nonene).

\section{KINETIC MODELING}

Detailed examination of a reaction network for complex processes like combustion can hardly be realized without detailed kinetic modeling. Additionally, reaction mechanisms for novel fuels must be developed, tested, and validated against experimental data. Thus, a first approach of chemical kinetic reproduction of the obtained experimental results is presented below.

\section{A. Approach}

As a first approximation, a plug flow approach can be assumed, i.e., diffusion, axial as well as radial, is neglected and uniform velocity is assumed. This allows for direct transformation of the spatial position $x$ to a distinct reaction (residence) time $\tau$ and consequently a simple OD consideration of the chemical kinetics (species and temperature evolution) as func- tion of reaction time only. Once the spatial temperature profile is known, it might be used as an input parameter for the reactor calculation to obtain the spatial (temporal) evolution of the participating species. Respective plug flow reactor modules are available in most commercial and open source chemical kinetics software tools. However, the experiment provides the gas phase composition at a distinct reactor coordinate $x$, while varying reactor temperature (i.e., temperature profiles) is applied.

For a reasonable simulation of the experimental mole fraction profiles, Eq. (3) can be used to obtain axial temperature profiles for any oven temperature. Figure 9 gives the axial mole fraction profiles of formaldehyde and acetylene for four selected oven temperatures for a stoichiometric $\mathrm{CH}_{4}$ measurement. Calculations are performed using the plug flow reactor module of Chemical Work Bench ${ }^{66}$ (CWB) with a respective temperature profile obtained from the scaling law as given in Fig. 9. The software offers the possibility to perform individual calculations for a high number of input temperature profiles, which enables the application of small (oven) temperature increments. The results of the individual calculations at the sampling position can be subsequently compared to the experimental results. It was found that increments below $1 \mathrm{~K}$ do not change the resulting mole fraction profiles.

The obtained calculation results performed with the widely validated USC-II mechanism ${ }^{57}$ are also presented in

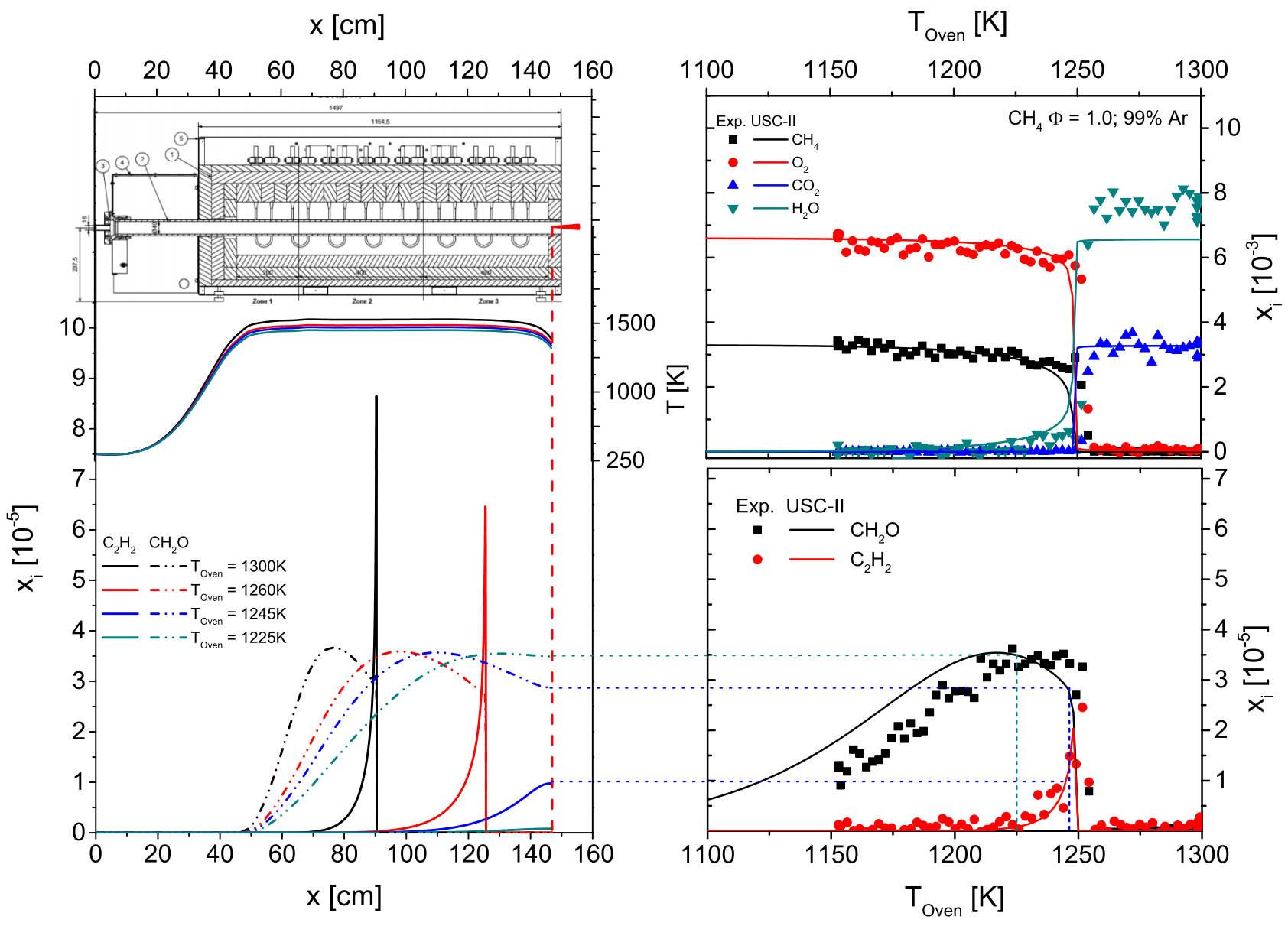

FIG. 9. Kinetic modeling of stoichiometric methane oxidation using the USC-II mechanism. Left: spatial model result (lines) for mole fraction profiles of acetylene $\left(\mathrm{C}_{2} \mathrm{H}_{2}\right)$ and formaldehyde $\left(\mathrm{CH}_{2} \mathrm{O}\right)$ at selected oven temperatures and the respective temperature profiles (right axis) and right: comparison to the experimental results (symbols) of intermediate (bottom) and major species (top) when temperature ramps are considered. 
Fig. 9 and an excellent agreement can be stated. It should be noted that no adjustments of temperature or mole fraction axes have been made. This good agreement gives some confidence that the approximations and assumption made for the simulations are valid. In particular, this includes plug flow conditions with negligible diffusion, validity of the temperature profiles and the scaling law (see Section III A), respectively, negligible heat release and wall reactions.

\section{B. Results}

Chemical kinetics simulations are performed this way for the $\mathrm{CH}_{4}$ and $\mathrm{C}_{2} \mathrm{H}_{4}$ measurements described in Section IV A covering the stoichiometries $0.5,1.0$, and 2.0 for each fuel. Different reaction models are taken from the literature and are tested against the experimental results: for methane, USCII-mechanism and GRI 3.0, ${ }^{64}$ for ethylene, USC-II ${ }^{57}$ and a mechanism for large alkanes from Lawrence Livermore National Laboratory $\left(\mathrm{LLNL}^{59}\right)$. In general, the prediction of the major species is good for the complete dataset. Deviations may occur for the ignition temperature of the ethylene fuel. The experimental finding, however, is exactly between the predictions of both models.

Good agreement was also found for most intermediate species of methane, while larger deviations are found for

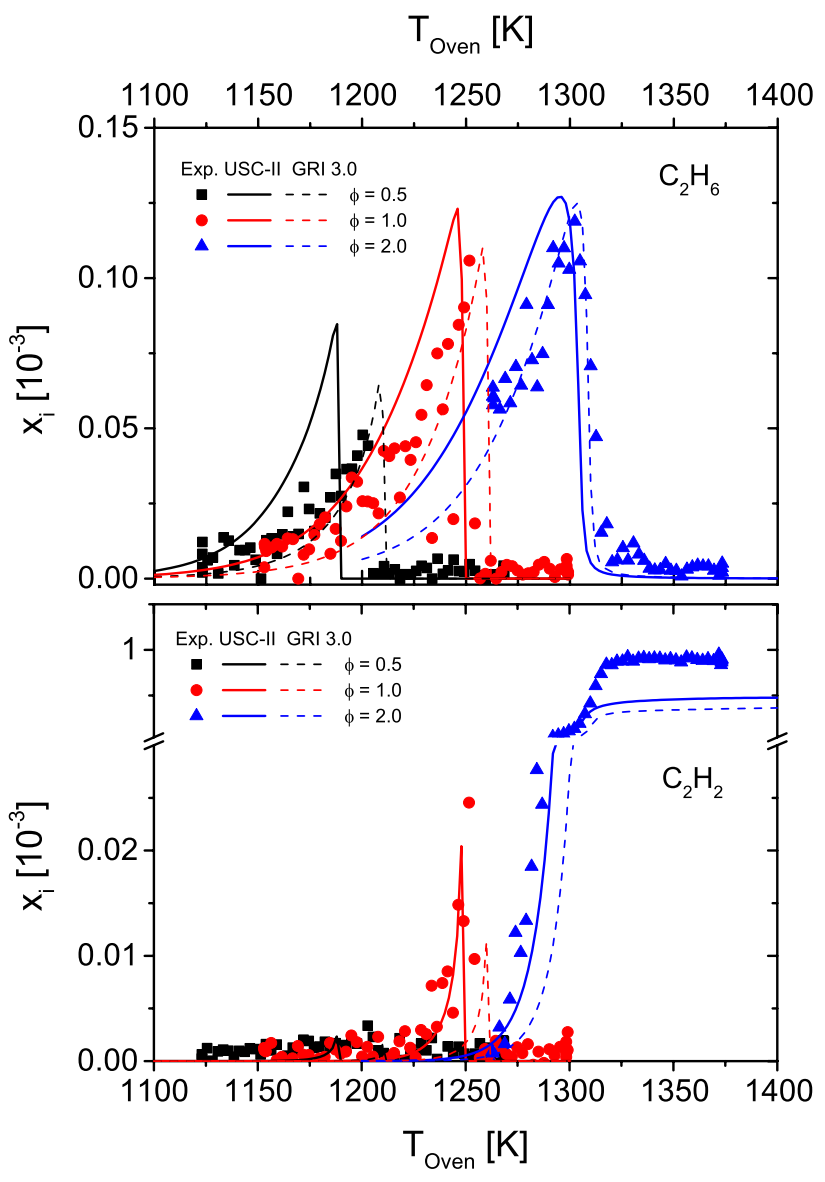

FIG. 10. Intermediate profiles (top: ethane; bottom: acetylene) from $\mathrm{CH}_{4}$ oxidation; selected results for different mechanisms (lines) and stoichiometries $(\phi)$ compared to experimental results (symbols); full dataset is available in the supplementary material. ${ }^{52}$ ethane and some of the lean conditions. It should be noted that the deviation between the applied kinetic models is also significant for these conditions. This can be taken as evidence for needed improvements of the reaction kinetics at these conditions. Figure 10 gives some examples for selected species of the methane series. Results for all species, fuels and conditions are shown in the supplementary material. ${ }^{52}$ For $\mathrm{CH}_{4}$, additional results obtained at higher electron energy are given and provide a more precise determination of the major species. A detailed discussion of all individual features is beyond the scope of the present work. However, the good agreement of most species profiles proves the ability of the present experiment to serve as a powerful validation experiment for chemical kinetics. Deviations on the other hand underline the demand of such experiments for further improvement of the respective models.

\section{SUMMARY}

A new high-temperature flow reactor experiment utilizing the powerful MBMS technique for detailed speciation is presented. Temperatures up to $1800 \mathrm{~K}$ are applicable by three individually controlled temperature zones with this atmospheric pressure reactor. Detailed speciation data are obtained using the sensitive MBMS technique providing access to almost all chemical species involved in the combustion process including highly reactive species such as radicals.

Strategies for quantifying the experimental data are presented alongside a careful analysis of the characterization of the experimental boundary conditions to enable precise numeric reproduction of the experimental results. First and foremost, the temperature behavior is explored in detail, providing an experimentally determined scaling law to obtain full temperature profiles for any oven temperature. The general procedures for the quantitative data evolution may follow the same strategies for flame and reactor experiments.

The general capabilities of this new analytical tool for the investigation of reacting flows are demonstrated for a selected range of conditions, fuels, and applications. Starting from well-known gaseous fuels like methane and ethylene, liquid fuels, and fuel components important for technical applications in gas turbines and combustion engines are examined. Due to the high sensitivity of the MBMS detection, examination of the full reaction network of novel fuels can be observed including soot precursor chemistry and radical species. Consequently, this appears to be the first reactor experiment allowing for radical detection at atmospheric conditions.

Besides the application for detailed investigation of novel fuels and fuel components, the superior range of operation conditions gives access to extraordinary combustion applications such as super rich conditions at high temperature important for gasification processes or the peroxy chemistry governing the low temperature oxidation regime. These demonstrations are accompanied by a first kinetic modeling approach, highlighting the opportunities for model validation purposes. The obtained species profiles are reproduced by a kinetic reaction model using a plug flow approximation of comparable quality as known from common MBMS experiments. 


\section{ACKNOWLEDGMENTS}

The authors wish to thank Georg Eckel, Patrick Le Clercq, and Uwe Riedel for fruitful discussions on the reactor layout. Jakub Kaleta, Larissa Kracht, and Ryan Whitside are gratefully acknowledged for their help with installation, measurements, and preparation of this manuscript. The authors are thankful for funding by the Helmholtz Association as well as support from the DLR Center-of-Excellence "Alternative Fuels."

${ }^{1}$ F. N. Egolfopoulos, N. Hansen, Y. Ju, K. Kohse-Höinghaus, C. K. Law, and F. Qi, Prog. Energy Combust. Sci. 43, 36 (2014).

${ }^{2}$ F. Battin-Leclerc, Prog. Energy Combust. Sci. 34, 440 (2008).

${ }^{3}$ R. K. Hanson and D. F. Davidson, Prog. Energy Combust. Sci. 44, 103 (2014).

${ }^{4}$ P. T. Lynch, T. P. Troy, M. Ahmed, and R. S. Tranter, Anal. Chem. 87, 2345 (2015).

${ }^{5}$ C.-J. Sung and H. J. Curran, Prog. Energy Combust. Sci. 44, 1 (2014).

${ }^{6}$ C. L. Rasmussen, J. Hansen, P. Marshall, and P. Glarborg, Int. J. Chem. Kinet. 40, 454 (2008).

${ }^{7}$ T. A. Ano and F. L. Dryer, Symp. (Int.) Combust., [Proc.] 27, 397 (1998).

${ }^{8}$ C. C. Schmidt and C. T. Bowman, Combust. Flame 127, 1958 (2001).

${ }^{9}$ L. Marrodán, Á Millera, R. Bilbao, and M. U. Alzueta, Energy Fuels 28, 6107 (2014).

${ }^{10}$ S. M. Sarathy, S. Gaïl, S. A. Syed, M. J. Thomson, and P. Dagaut, Proc. Combust. Inst. 31, 1015 (2007).

${ }^{11}$ P. Dagaut, M. Reuillon, and M. Cathonnet, Combust. Sci. Technol. 95, 233 (1993).

${ }^{12}$ F. Battin-Leclerc, O. Herbinet, P. A. Glaude, R. Fournet, Z. Zhou, L. Deng, H. Guo, M. Xie, and F. Qi, Angew. Chem., Int. Ed. 49, 3169 (2010).

${ }^{13}$ T. Wada, A. Sudholt, H. Pitsch, and N. Peters, Combust. Theory Modell. 17, 906 (2013).

${ }^{14}$ D. Fleig, M. U. Alzueta, F. Normann, M. Abián, K. Andersson, and F. Johnsson, Combust. Flame 160, 1142 (2013).

${ }^{15}$ F. Herrmann, P. Oßwald, and K. Kohse-Höinghaus, Proc. Combust. Inst. 34, 771 (2013).

${ }^{16}$ J. Cai, L. Zhang, J. Yang, Y. Li, L. Zhao, and F. Qi, Energy 43, 94 (2012).

${ }^{17}$ K. Brezinsky, T. A. Litzinger, and I. Glassman, Int. J. Chem. Kinet. 16, 1053 (1984).

${ }^{18}$ M. A. Mueller, T. J. Kim, R. A. Yetter, and F. L. Dryer, Int. J. Chem. Kinet. 31, 113 (1999).

${ }^{19}$ Y. Zhang, J. Cai, L. Zhao, J. Yang, H. Jin, Z. Cheng, Y. Li, L. Zhang, and F. Qi, Combust. Flame 159, 905 (2012).

${ }^{20}$ T. Zhang, J. Wang, T. Yuan, X. Hong, L. Zhang, and F. Qi, J. Phys. Chem. A 112, 10487 (2008)

${ }^{21}$ N. M. Donahue, J. S. Clarke, K. L. Demerjian, and J. G. Anderson, J. Phys. Chem. 100, 5821 (1996).

${ }^{22}$ N. M. Kidwell, V. Vaquero-Vara, T. K. Ormond, G. T. Buckingham, D. Zhang, D. N. Mehta-Hurt, L. McCaslin, M. R. Nimlos, J. W. Daily, B. C. Dian, J. F. Stanton, G. B. Ellison, and T. S. Zwier, J. Phys. Chem. Lett. 5, 2201 (2014).

${ }^{23}$ D. W. Kohn, H. Clauberg, and P. Chen, Rev. Sci. Instrum. 63, 4003 (1992).

${ }^{24}$ Z. Wang, X. Zhang, L. Xing, L. Zhang, F. Herrmann, K. Moshammer, F. Qi, and K. Kohse-Höinghaus, Combust. Flame 162, 1113 (2015).

${ }^{25}$ J. Giménez-López, M. Martínez, A. Millera, R. Bilbao, and M. U. Alzueta, Combust. Flame 158, 48 (2011).

${ }^{26}$ P. G. Kristensen, P. Glarborg, and K. Dam-Johansen, Combust. Flame 107, 211 (1996).

${ }^{27}$ D. Wenli, K. Dam-Johansen, and K. Østergaard, Symp. (Int.) Combust., [Proc.] 23, 297 (1991).

${ }^{28}$ R. A. Yetter, F. L. Dryer, and H. Rabitz, Combust. Sci. Technol. 79, 129 (1991).

${ }^{29}$ H. H. Grotheer, G. Riekert, D. Walter, and T. Just, Chem. Phys. Lett. 148, 530 (1988).

${ }^{30}$ F. L. Dryer, F. M. Haas, J. Santner, T. I. Farouk, and M. Chaos, Prog. Energy Combust. Sci. 44, 19 (2014).

${ }^{31}$ G. C. Eltenton, J. Chem Phys. 15, 455 (1947).

${ }^{32}$ F. Qi, Proc. Combust. Inst. 34, 33 (2013).

${ }^{33}$ C. A. Taatjes, N. Hansen, D. L. Osborn, K. Kohse-Höinghaus, T. A. Cool, and P. R. Westmoreland, Phys. Chem. Chem. Phys. 10, 20 (2008).
${ }^{34}$ P. Hemberger, A. J. Trevitt, E. Ross, and G. da Silva, J. Phys. Chem. Lett. 4, 2546 (2013).

${ }^{35}$ P. Oßwald, P. Hemberger, T. Bierkandt, E. Akyildiz, M. Köhler, A. Bodi, T. Gerber, and T. Kasper, Rev. Sci. Instrum. 85, 025101 (2014).

${ }^{36}$ N. Hansen, T. A. Cool, P. R. Westmoreland, and K. Kohse-Höinghaus, Prog. Energy Combust. Sci. 35, 168 (2009).

${ }^{37}$ P. Oßwald, K. Kohse-Höinghaus, U. Struckmeier, T. Zeuch, L. Seidel, L. Leon, and F. Mauss, Z. Phys. Chem. 225, 1029 (2011).

${ }^{38}$ K. Kohse-Höinghaus, P. Oßwald, T. A. Cool, T. Kasper, N. Hansen, F. Qi, C. K. Westbrook, and P. R. Westmoreland, Angew. Chem., Int. Ed. 49, 3572 (2010).

${ }^{39}$ S. M. Sarathy, P. Oßwald, N. Hansen, and K. Kohse-Höinghaus, Prog. Energy Combust. Sci. 44, 40 (2014).

${ }^{40}$ D. F. Schuler, C. Naumann, M. Braun-Unkhoff, U. Riedel, and F. Zabel, Z. Phys. Chem. 229, 529 (2015).

${ }^{41}$ P. Dagaut, F. Karsenty, G. Dayma, P. Diévart, K. Hadj-Ali, A. Mzé-Ahmed, M. Braun-Unkhoff, J. Herzler, T. Kathrotia, T. Kick, C. Naumann, U. Riedel, and L. Thomas, Combust. Flame 161, 835 (2014).

${ }^{42}$ M. Köhler, T. Kathrotia, P. Oßwald, M. L. Fischer-Tammer, K. Moshammer, and U. Riedel, Combust. Flame 162, 3197 (2015).

${ }^{43}$ P. Oßwald, H. Güldenberg, K. Kohse-Höinghaus, B. Yang, T. Yuan, and F. Qi, Combust. Flame 158, 2 (2011).

${ }^{44}$ M. Schenk, L. Leon, K. Moshammer, P. Oßwald, T. Zeuch, L. Seidel, F. Mauss, and K. Kohse-Höinghaus, Combust. Flame 160, 487 (2013).

${ }^{45}$ U. Struckmeier, P. Oßwald, T. Kasper, L. Böhling, M. Heusing, M. Köhler, A. Brockhinke, and K. Kohse-Höinghaus, Z. Phys. Chem. 223, 503 (2009).

${ }^{46}$ K. Zhang, K. Moshammer, P. Oßwald, and K. Kohse-Höinghaus, Proc. Combust. Inst. 34, 763 (2013).

${ }^{47}$ J. C. Biordi, Prog. Energy. Combust. Sci. 3, 151 (1977).

${ }^{48}$ H. H. Grotheer, H. Pokorny, K. L. Barth, M. Thierley, and M. Aigner, Chemosphere 57, 1335 (2004).

${ }^{49}$ H. H. Grotheer, K. Wolf, and K. Hoffmann, Appl. Phys. B 104, 367 (2011).

${ }^{50}$ U. Boesl, R. Weinkauf, and E. W. Schlag, Int. J. Mass Spectrom. Ion Processes 112, 121 (1992).

${ }^{51}$ F. Herrmann, B. Jochim, P. Oßwald, L. Cai, H. Pitsch, and K. KohseHöinghaus, Combust. Flame 161, 384 (2014).

${ }^{52}$ See supplementary material at http://dx.doi.org/10.1063/1.4932608 for a detailed description of data evaluation procedures and complete $\mathrm{CH}_{4}$ and $\mathrm{C}_{2} \mathrm{H}_{4}$ dataset.

${ }^{53}$ N. Bahlawane, U. Struckmeier, T. Kasper, and P. Oßwald, Rev. Sci. Instrum. 78, 013905 (2007).

${ }^{54}$ T. Kasper, U. Struckmeier, P. Oßwald, and K. Kohse-Höinghaus, Proc. Combust. Inst. 32, 1285 (2009).

${ }^{55}$ T. Kasper, P. Oßwald, U. Struckmeier, K. Kohse-Höinghaus, C. A. Taatjes, J. Wang, T. A. Cool, M. E. Law, A. Morel, and P. R. Westmoreland, Combust. Flame 156, 1181 (2009).

${ }^{56}$ A. Lucassen, P. Oßwald, U. Struckmeier, K. Kohse-Höinghaus, T. Kasper, N. Hansen, T. A. Cool, and P. R. Westmoreland, Proc. Combust. Inst. 32, 1269 (2009)

${ }^{57}$ H. Wang, X. You, A. V. Joshi, S. G. Davis, A. Laskin, F. N. Egolfopoulos, and C. K. Law, USC Mech Version II. High-Temperature Combustion Reaction Model of $\mathrm{H}_{2} / \mathrm{CO} / \mathrm{C1}$-C4 Compounds (2007), available online at http://ignis. usc.edu/USC_Mech_II.htm.

${ }^{58}$ J. M. Simmie, Prog. Energy Combust. Sci. 29, 599 (2003).

${ }^{59}$ C. K. Westbrook, W. J. Pitz, O. Herbinet, H. J. Curran, and E. J. Silke, Combust. Flame 156, 181 (2009).

${ }^{60}$ W. Li, M. E. Law, P. R. Westmoreland, T. Kasper, N. Hansen, and K. KohseHöinghaus, Combust. Flame 158, 2077 (2011).

${ }^{61}$ B. Stelzner, F. Hunger, A. Laugwitz, M. Gräbner, S. Voss, K. Uebel, M. Schurz, R. Schimpke, S. Weise, S. Krzack, D. Trimis, C. Hasse, and B. Meyer, Fuel Process. Technol. 110, 33 (2013).

${ }^{62}$ F. Hunger, B. Stelzner, D. Trimis, and C. Hasse, Flow, Turbul. Combust. 90 , 833 (2012).

${ }^{63}$ M. Köhler, P. Oßwald, H.-B. Xu, C. Hasse, and U. Riedel, "Speciation data for fuel-rich methane oxy-combustion and reforming under prototypical partial oxidation conditions," Chem. Eng. Sci. (in press).

${ }^{64}$ G. P. Smith, D. M. Golden, M. Frenklach, N. W. Moriarty, B. Eiteneer, M. Goldenberg, C. T. Bowman, R. K. Hanson, S. Song, W. C. Gardiner, Jr., V. V. Lissianski, and Z. Qin, GRI-MECH 3.0, available online at http://www. me.berkeley.edu/gri_mech/.

${ }^{65}$ J. Zádor, C. A. Taatjes, and R. X. Fernandes, Prog. Energy Combust. Sci. 37, 371 (2011).

${ }^{66}$ Chemical WorkBench ${ }^{\circledR} 4.0$, Kintech Laboratory, available online at http:// www.kintechlab.com/products/chemical-workbench/. 